\title{
Rurality, ruins and archives: mapping the architectural history of the Greek countryside.
}

\author{
Afroditi Maragkou ${ }^{1}$ \\ ${ }^{1}$ University of Thessaly, Department of Architecture, 38334 Volos, Greece
}

\begin{abstract}
What remains unexamined and undervalued in the Greek landscape, are the extreme and abandoned limits of the small nonmetropolitan regional areas. At the limits of Greek cities, we can identify a great dispersion, a marginal instability, states of transition and deposition. The architectural and planning policies of the Greek state, through the modernistic period, have set a significant number of traces on the rural part of the country. These traces on the countryside, can only be recorded and historically analysed through systematic approach and subjective mapping, such as the methodology of oral history promotes. The landscape of the lowlands of Thessaly is selected as a paradigm of a changing reality, where one can see and recognize a number of exemplary transformations and specificities. The resettlement phenomenon of the mountain populations in Karditsa region, which was affected by the reclamation infrastructure of the 1960s (construction of Megdova dam), is the springboard for a dispersion of new residential settlements in the lowlands. This relocation process had a significant impact on the transformation of the rural landscape of Thessaly, as well as on the social life of the countryside. The architectural and historical research is motivated from the current ruin condition of these promising residential settlements on the countryside of Thessaly and systematically examines the policies that lead from the construction of Megdova dam to these abandoned traces on the landscape. The methodology of this research is based on an ongoing microhistorical archive which aims to raise microhistory as the main interpretation tool. Composed by oral testimonies, historical sources, state documents, blueprints and other official recordings, this microhistorical archive will be able to map and interpret the architectural, topological and social history of these modernistic interventions on the countryside of Thessaly.
\end{abstract}

\section{Introduction}

In order to understand the profile of the Greek nation's topological and architectural history after World War II and the civil war that followed, we should emphasize at the national reconstruction attempt that had its beginning in 1947. The Reconstruction Organization compiled by a transdisciplinary team of experts, set the ground for a

\footnotetext{
${ }^{1}$ Afroditi Maragkou: afro.maragkou@gmail.com
} 
significant number of infrastructural and architectural projects. We can recognize in this national reconstruction team the personality of Konstantinos Doxiadis, who seemed to have a much more insightful view for this context. The aspects of this reconstruction process were to reconstruct the war damage in the country and to implement new productive large scale development projects. The design and implementation of these projects had various impacts on the transformation of the urban but much more on the rural parts of Greece. The evolution of the rural habitation system, deeply affected by these national development projects, can provide us with significant information on the social impact of the modernization processes. However, in order to thoroughly investigate all the details of these impacts, the research presented here is concentrated on a single micro-historical case study on the lowlands of Thessaly, which, as an indicative example, aims to supply and broaden the desirable field of research.

The landscape of the lowlands of Thessaly, which is located in the north-central part of Greece, summarizes the identities, specificities and changes of the rural habitation process of the country. The field observation and investigation of this landscape is not limited to the data of the geographical boundaries, but considers the landscape as an open field of correlations and interactions. Therefore, in order to understand the character of the landscape, we must at first understand the relationships between the state processes and the local communities acting in it [1].

\section{Evolution of the rural habitation system in the internal part of the countryside of Thessaly}

\section{The moving rural family phenomenon}

The importance of the evolution of the residential system in the countryside of Thessaly can be summarised in relation to the phenomenon of the "moving rural family". The population analysis in rural settlements in the lowlands reveals the changes caused by various population movements in the residential system itself. These movements were the result of a clear concentration of population, not only in the capitals of the counties but also in the rural towns [2]. The destination of the moving rural family was determined by the effort to organize the employment of its members, their homes and necessary amenities into feasible time-distances and functional areas. The pursuit of such a combined spatial organization was determined by the fact that the residential system of Thessaly was characterized by numerous densely distributed small villages, particularly in western Thessaly.

\section{Displacement and relocation}

As an evolution of the phenomenon of the "moving rural family", an important and multidimensional project that contributed to the organization of rural habitation system was the displacement and relocation of entire settlements. Key factors of these rapid, ongoing and somewhat violent transformations of the rural landscape were all the development projects that the acceleration of modernisation of the 1960s brought, such as the extension of basic infrastructure, electrification and the national road network. All these development projects had a direct impact on the unequal development of the of rural landscape regions and were the cause of the displacement and resettlement of populations in general.

The dimensions of this phenomenon were political, social, economic, spatial and technical. Political, because they reflect the unwillingness of the Government and other 
planning agencies to protect the quality of life of residents in conjunction with the promotion of the development process. Social, because entire societies were moved away from the place they grew up, created their families, developed professional activities and finally they were emotionally tied to each other and to the spaces filled with memories. Economic, since the inhabitants of these settlements developed economic activities which, in many cases, were inseparably linked to the specific area and were uniquely associated or largely affected by it. Especially, in the case of rural families, the place of residence is generally the same as the place of economic activity, that is their cultivated land. In addition, on a spatial level, the new residential locations had to combine a range of parameters, in order to respond to some basic principles, such as the viability of the new settlements.

\section{The resettlement practice in Karditsa region}

\section{Construction of Megdova dam}

This resettlement practice had a strong application in the landscape of rural Thessaly and in particular in the broader region of Karditsa city. The mountain region of Plastiras Lake shows all the typical characteristics of a declining mountainous area: sever population aging and underemployment within a dominant extensive farming and forestry sector. The construction of Plastiras Lake (1959-1962) (Fig. 1), undertaken to supply water and to irrigate the valley, resulted in the dissolution of the local agricultural and livestock production systems and the migration of residents to the neighbouring plains and cities. The loss of this living space had its impact on the disruption of the contact and social presence of lakeside villages [3].

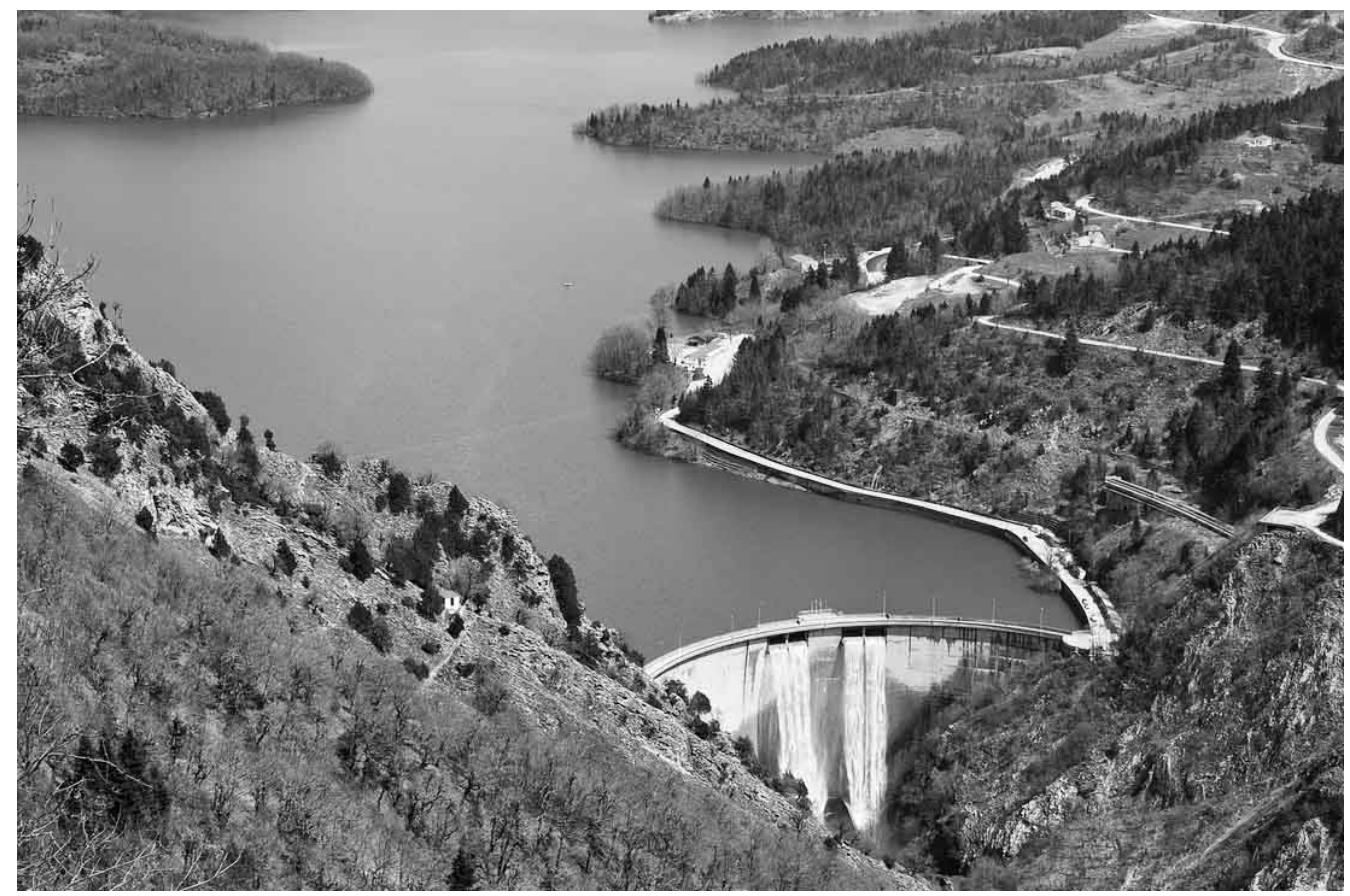

Fig. 1. Lake Plastiras and Megdova dam, Topographic service of Karditsa city, May 2015 
In the early 1960s the construction of Plastiras lake, located on the plateau of Nevropolis in Karditsa region, caused a special agreement for population transfer. Nikolaos Plastiras conceived the idea of creating the artificial lake on the plateau of Nevropoli Agrafon, which is crossed by the River Megdovas. The lake would be used for the irrigation of the plain of the prefecture of Karditsa. The decision to construct the Megdova dam was taken on 12 December 1961.

The mountain populations affected by the project were moved to properties that were located on the boundaries of existing villages in the plain of Karditsa. These new settlements were meant for both housing rehabilitation and work, as they were granted property and sections of arable land. The residential settlements established in each village on the lowlands were supposed to accommodate different numbers of people. Assignments were made from a village of the lake region to a village on the lowlands, and this number varied from village to village.

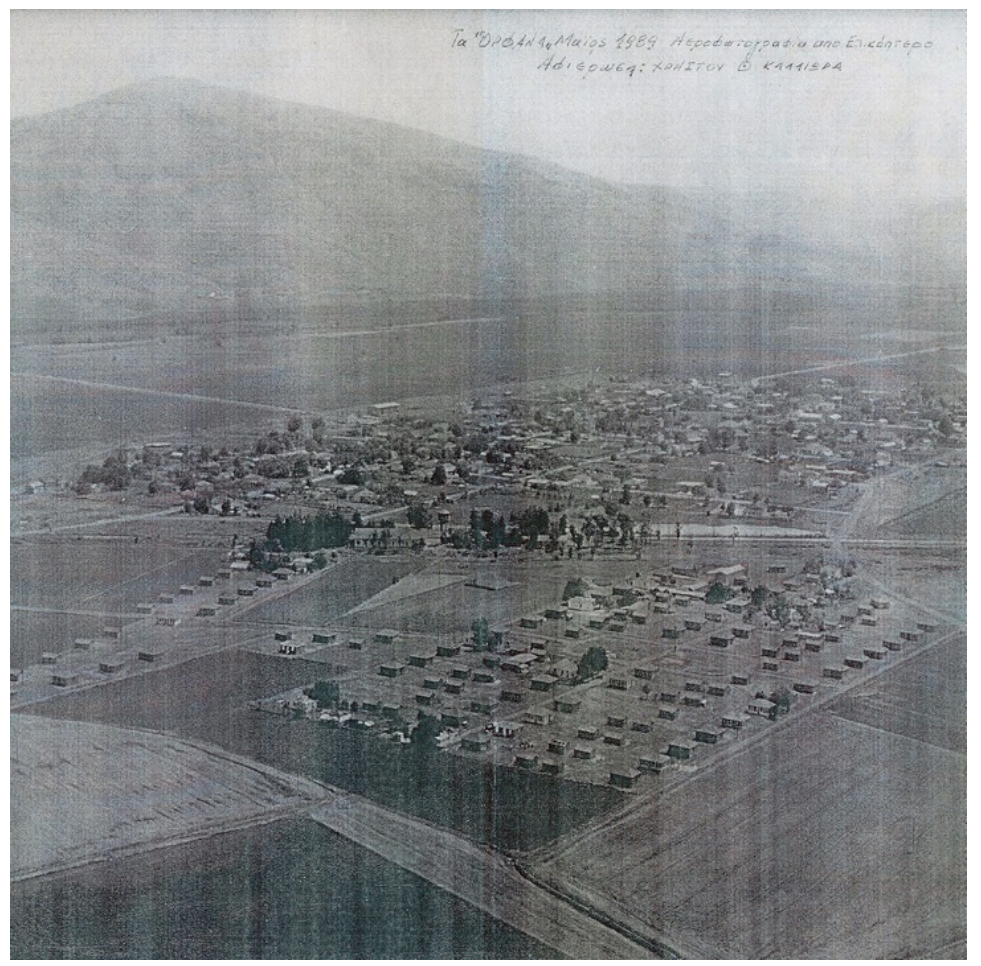

Fig. 2. The abandoned settlement in Orfana village.

Source: Christos Kallioras, Palamas Mortage office, May 1989.

\section{The new residential settlements and their abandonment}

A very special case of settlement created by the displacement of these mountain populations can be found in Orfana village. When visiting the new village, one is confronted with an image of a settlement strictly separated from main village, in complete desolation and abandonment. This settlement, having a strictly organized spatial structure represents traces of the failed era of dynamic ventures without a counterpart of dynamic programming. It is located on the periphery of the original Orfana village and consists of 92 properties. It is a settlement of which the majority of houses have never been inhabited. Most buildings are still in their original brick form. They are abandoned and the majority of them are in a ruined state. Some of them have been 
plastered and painted white but still uninhabited. Abandonment is visible from afar and raises questions around the notion of the rural ruin, its traces on the landscape and the socio-political context in which it was formed.

\section{The ruin and the archive}

\section{The microhistory of the countryside}

At this point it is necessary to emphasises that the research of this specific case study of displacement is based on the theory of "microhistory" as described by Carlo Ginzburg. The concept of microhistory, as a methodological and interpretative tool of historical research, is based on the principle that the selection of a small-scale observation can produce significant results and can also be a tool of a more general strategy [4]. The "indicative example" is considered to be a key element of this method, from which begins the establishment of a unifying framework in order to observe also the "global". According to Ginzburg, "the constant and intensive analysis of a single case study is able to lead to a proper generalization" [5]. In my case, the "indicative example" is the constant and intensive study of this ruined residential settlement on the landscape of Thessaly along with the traces of resettlement. Thus, this microhistory of a single and phenomenologically minor case study in the rural part of Greece may illuminate the general context of similar cases of displacement due to state policies found in the modern world.

The basic interpretational tool of this observation is the synthesis of an interdisciplinary archive.

\section{The archival practice as methodology}

The archival practice, in the form of indexes, directories, registries, etc. was one of the mechanisms by which the rational regulation of modernity took place. At the same time, the archive, as one of the sciences of modernity, as Foucault points out, is characterized by the possibility of decentralization, "the common tactic of being able to take distance in a self-critical way from its own traditions" [6]. Thus, this characteristic of archival practice will lead the research towards a more objective mapping of the case study.

As an interpretative mechanism, this "micro-historical" archive was organized through field visits, initially in the wider region of the Megdova dam and then at the microscale of the resettled residential settlements. Some idea of the sources of field research for the collection of archive material include the Greek State's General Archives (department of Karditsa city), the Palamas Mortgage Office, municipal libraries of the whole Prefecture, the Topographic Service of Karditsa city, the Ministry of Rural Development and the archives of the Agricultural Bank of Greece.

At the same time, the interdisciplinary nature of the archival recording of the events that contributed to this case of the ruins can be highlighted through the tool of oral history. Oral history, as a collection of testimonies and experiences, is structured around people by animating the story itself and expanding its horizons [7]. An attempt at a historical record "from the inside" is made by taking the subjects who were part of this case of abandonment as objective narrative actors. The process of oral history is an integral part of the archival record, which, among other things, is used to confirm or deny the narrative that produced from the other sources. 


\section{Mapping and interpretation}

\section{Mapping the state of ruin}

The state of ruin, in which I observed the physical legacy of this modernization process that took place in the landscape of Thessaly, is the springboard for the archival mapping.

The research began with the memories, stories and voices of people who lived through the modernization process of the construction of Megdova dam. The use of oral sources creates new perspectives that go beyond the level of events, structures and behaviours and illuminate the place in which they are experienced, kept alive, and are used to interpret the past and present of individual and collective subjects. History obtains a new dimension once the experiences of every kind of people are used as the primary source [8]. Interviews also reveal documents, photographs (archive material) that cannot otherwise be interpreted. In this case, the survey of the interviews was initiated through the microhistory of the resettlement practice at the ruined residential settlement at Orfana. The only two families still living in the settlement provided the first oral testimonies to start revealing all the transformations of the social structures due to the construction of Megdova dam and the resettlement. They families were identified at the site of the study, the abandoned settlement, and proved willing to give an interview. An interview, in a free flow form, was chosen in order to highlight the narrative and subjectivity of the story. The purpose of the research is to structure these narratives and to analyse the different types of evidence in order to construct the history and archive of the settlement.

These first two oral testimonies opened the horizons of the mapping to many sources of archival material able to be used to construct and interpret the history and the impacts of this modernization process in the countryside of Thessaly.

\section{Interpreting the history of the countryside of Thessaly}

The ongoing interdisciplinary archive composed through the method and mapping described above, provides significant aspects of the anthropology of the rural social, the role of the political systems in rural settlement planning as well as the spatial and architectural models of inhabitation.

At first, from the oral testimonies of the only remaining inhabitants of the resettled residential settlement in Orfana, a feeling of spatial "discrimination" from the inhabitants of the existing village was revealed. The designed settlement predefined for the move of the population from the mountainous area of Lake Plastiras, was laid out on the periphery of the existing village of Orfana, with the railway line as a strict border. From the official state blueprints, we can identify this spatial planning, that led to the lack of either visual or social contact between the original and the resettled inhabitants. This was a significant deterrent to the incoming population moving to the new settlement.

Secondly, through examining the official state laws when the construction of Megdova dam took place, we can identify the unwillingness of the political system to give any emphasis to the social-anthropological profile of the resettled populations in contrast to the focus on the strict technical aspects of the work constructing new residential areas. As a result, the mountain people ended up in the lowland countryside, having no experience of farming on such different land. The houses they were given came with allocated farmland, but the products from such farming which were supposed to support the people economically, were unfamiliar and difficult for them to produce. 
Last but not least, the rural architectural pattern used from the state's design agency lacked flexibility for any personal modification. A single rectangular residence along with one smaller rectangular barn were designed without taking into consideration the profile of the different families that were supposed to live in them. As a consequence, the majority of the moving families were unwilling to even finish the construction of these houses and sold them straightaway in pursuit of a more traditional house in the city of Karditsa.

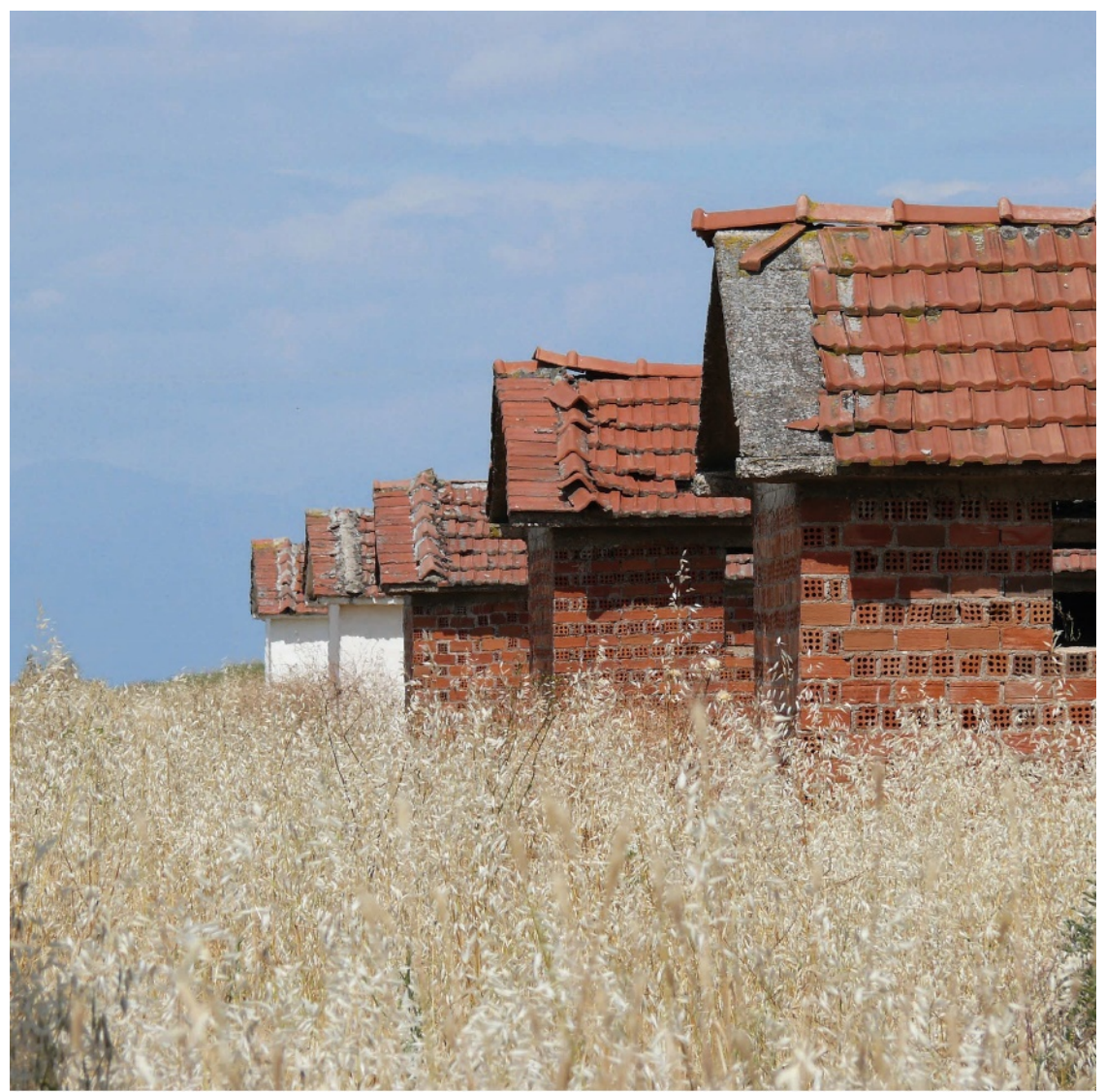

Fig. 3. The abandoned settlement in Orfana village, Personal Archive, June 2016

\section{Conclusions}

The microhistory of the ruined settlement in Orfana village, read and analysed through an interdisciplinary archive, produced a narrative that can be recognized in a lot of cases of rural resettlement due to infrastructure project development not only in the Greek landscape but also more widely. The methodology to broaden the research on the impacts of such modernization processes on the landscape, should not be limited to a strict discipline, such as history, architecture or sociology, but should make use of all the data provided by these disciplines in order to compose a trans-disciplinary uncontested archival record. Such archival records are able to illuminate the 
"unconscious" of the rural landscape and possibly to redefine the terms and practices of the population resettlement.

\section{Short resume}

Afroditi Maragkou is an Architect, with a MSc degree in Architectural Design and is currently a $\mathrm{PhD}$ candidate in the Department of Architecture, University of Thessaly, Greece. She has participated as a speaker in international architectural congresses, been an assistant curator in architectural workshops and exhibitions and has published articles in Greek architectural magazines. She is an assistant undergraduate tutor in the Department of Architecture, University of Thessaly and at simultaneously works as a licensed architect in Trikala. Her academic research focuses in the architectural theory and history of ruins through archival interpretations.

\section{References}

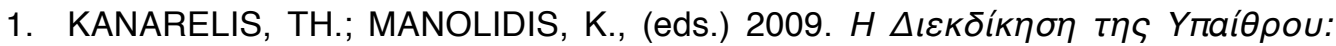

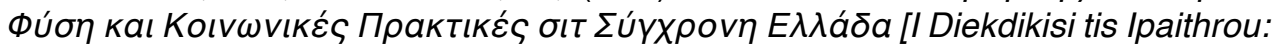
Fisi kai Koinonikes Praktikes sit Sigchroni Ellada / Claiming the Countryside. Nature and Social Practices in Contemporary Greece], Athens, Indictos.

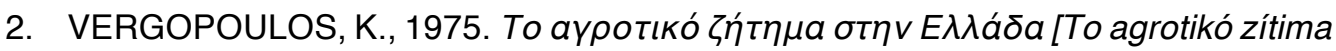
stin Elláda / The Rural Issue in Greece], Athens, Exantas [republ. in French as: (1977). Le Capitalisme Difforme et la Nouvelle Question Agraire, L'Exemple de la Grèce Moderne, Paris, Maspero].

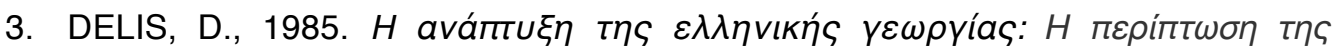

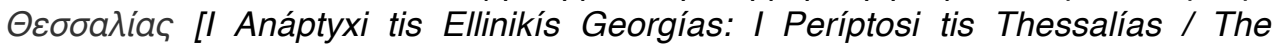
Development of Greek Agriculture. The Case of Thessaly], Athens, Agricultural Bank of Greece.

4. GINZBURG, C., (1992) 2013. Clues, Myths and the Historical Method, Baltimore, John Hopkins University Press.

5. GINZBURG, C., (1976) 2013. The Cheese and the Worms. The Cosmos of a Sixteenth Century Miller, Baltimore, John Hopkins University Press.

6. FOUCAULT, M. (1969) 2002. The Archaelogy of Knowledge (transl. by A. M. Sheridan Smith), Abingdon, Routledge.

7. ABRAMS, L., 2010, Oral History Theory, Abingdon, Routledge. DOI: https:// doi.org/10.4324/9780203849033

8. THOMSON, P. (1978) 2000. The Voice of the Past. Oral History, Oxford (NY), Oxford University Press. 